\title{
Regularity of clinical visits and medication adherence of patients with hypertension or diabetes in rural Yunnan province of China
}

\section{Qiufeng Gao}

Shaanxi Normal University

\section{Lanxi Peng}

Shaanxi Normal University

\section{Wenbin Min}

Shaanxi Normal University

Jingchun Nie

Shaanxi Normal University

Aiqin Wang ( $\nabla$ shxiwangaiq@163.com )

Shaanxi Normal University https://orcid.org/0000-0002-2243-9677

\section{Hongmei Yi}

Peking University

\section{Yaojiang Shi}

Shaanxi Normal University

\section{Dirk E. Teuwen}

UCB Pharma SA

Haonan Shi

Red Cross Society of China

\section{Research article}

Keywords: diabetes, hypertension, clinical visits, medication adherence

Posted Date: August 1st, 2020

DOI: https://doi.org/10.21203/rs.3.rs-42829/v1

License: (c) (i) This work is licensed under a Creative Commons Attribution 4.0 International License. Read Full License

Version of Record: A version of this preprint was published at International Journal of Environmental Research and Public Health on December 12th, 2020. See the published version at 
https://doi.org/10.3390/ijerph17249297. 


\section{Abstract}

Objective Chronic diseases can be controlled through effective self-management. The purpose of this study is to explore the regularity of clinical visits and medication adherence of patients with hypertension or diabetes (PDH), and its association with the first experience with care and individual factors in rural Southwestern China.

Methods The authors draw on a dataset which comprised of $292 \mathrm{PDH}$ and 122 village clinics selected from 122 villages in 10 counties in the rural areas of Yunnan province. Data was gathered through interviews with these patients and the directors of the village clinics in January 2018. Logistic regression models were performed using STATA 15.0.

Results The data shows around $31 \%$ of hypertensive and $25 \%$ of diabetic patients neither visited physicians nor took medicine regularly during the preceding three months of the interview date. We also documented PDH first experience with care and found that a proportion of them did not initially choose to seek care from health facilities. The logistic regression results indicated that individual characteristics of the PDH, including patient age, health status, and economic level, as well as their first experience with care were significantly associated with their regular healthcare behavior. Moreover, in addition to providing medical services, on average each sample village clinic with around two physicians simultaneously managed 180 hypertensive and 45 diabetic patients.

Conclusions Our paper shows how current self-management trends among PDH in the sample area was unsatisfactory, threatening the effective control of hypertension and diabetes in China. Even though healthcare reforms in China have been launched since 2009, this study revealed the need for further reforms in terms of improving self-management. The authors recommend an increase in the quantity and the quality of human resources in the primary healthcare realm in rural China, which should help provide better education and supervision services for self-management.

\section{Introduction}

Hypertension and diabetes are two major public health problems in China, and their prevalence has been rising in recent years, (GBD 2013 Mortality and Causes of Death Collaborators, 2015; GBD 2016 Causes of Death Collaborators, 2017; Y. Xu et al., 2013). It is estimated that the prevalence of hypertension and diabetes is around $27 \%$ and $10 \%$, respectively, which are among the highest incidences of chronic disease in China (Hu et al., 2019; L. Wang et al., 2017; Z. Wang et al., 2018). Hypertension and diabetes are the main contributors to cardiovascular disease and the resulting high mortality rates. In 2018, cardiovascular diseases were the leading cause of mortality in China, especially for rural residents (Hu et al., 2019; National health and family planning commission, 2017). Moreover, as some international comparative studies have suggested, the high incidence of chronic illnesses such as hypertension and diabetes in China is a threat to global efforts to curb healthcare costs (Feng et al., 2016; International Diabetes Federation, 2019; Ma et al., 2017). 
In response to these challenges, the Chinese government implemented healthcare reform at a national scale in 2009 (CPC Central Committee \& State Council, 2009) to improve chronic diseases management, including hypertension and diabetes. Counting on government financial subsidies support, public health services such as diagnostic and treatment services are regularly delivered to patients with chronic diseases.

While effective treatments are available, roughly half of the patients with diabetes or hypertension (henceforth, $P D H$ ) do not self-manage correctly in rural China (Hou et al., 2016; Lei et al., 2012; H. Li et al., 2014). Self-management behavior such as health services utilization and adherence to medicinal treatments is critical for the control of diabetes and hypertension (Feng et al., 2016; Fortuna et al., 2018). Unfortunately, empirical findings demonstrated that a large number of PDH in China did not use the healthcare system and failed to take medicine regularly (He et al., 2016; Huang et al., 2006; Y. Li et al., 2016). The numbers are worse in rural areas given the relatively limited medical resources and lower educational levels of residents (Hou et al., 2016; Lei et al., 2012).

In this study, we investigate the regularity of clinical visits and medication adherence of PDH along with related factors in rural areas of Yunnan province in China. Yunnan is a multi-ethnic province where rural residents have wages below the national average (10,768 RMB vs 14,617 RMB) (National Bureau of Statistics of China, 2019), possibly contributing to the variation in self-management strategies. Currently, only a few studies have documented the regularity of clinical visits and medication adherence of PDH, and how past experience with care influences their self-management in rural Yunnan (Z. Wang et al., 2018). Additionally, there is limited understanding of the workload of village physicians on PDH management; these physicians are the gatekeepers on chronic management in rural China (Y. Li et al., 2016).

To better understand the current self-management of PDH in rural areas of Yunnan province in China, we (i) investigate the regularity of clinical visits and medication adherence of PDH, (ii) document the health seeking behavior of PDH at their first experience with care, (iii) examine factors related with the regularity of clinical visits and medication adherence, and (iv) evaluate the workload of village clinics in terms of PDH management.

\section{Methods}

\section{Sampling}

Within three selected three prefectures in Yunnan province, the sample was selected to be a certain degree of representativeness through a five-step process. Firstly, we excluded three urban counties and 13 minority counties from the three prefectures, keeping 15 Han-concentrated rural counties as our sampling frame. Secondly, we randomly selected 10 of the remaining counties. Thirdly, we used probability proportional to size (PPS) sampling, to randomly select 122 villages proportional to the number of villages in each county. Fourth, when visiting selected sample villages, we randomly selected about six households and included a village clinic (henceforth, $\mathrm{VC}$ ) that mainly serviced for the sample village.[1] In 
this way, we selected 744 households and 122 VC from 122 sample villages. Finally, we included PDH from these households and the director of these VC (Table 1). In total, $292 \mathrm{PDH}$ and directors for $122 \mathrm{VC}$ were interviewed, with a response rate of $100 \%$.

Table 1 Sample size of patients with hypertension or diabetes

\begin{tabular}{lccc}
\hline Number of diseases & Full sample & Hypertension & Diabetes \\
\hline One disease & 272 & 244 & 28 \\
Two diseases & 20 & 20 & 20 \\
Total & 292 & 264 & 48 \\
\hline
\end{tabular}

\section{Data collection}

In January 2018, using a four-block survey, we interviewed each PDH and the director of each VC. In the first block of the survey, specific questions were asked about the regularity of clinical visits and medication adherence of PDH. Specifically, we asked whether the participant consulted with a doctor regularly and about their medicine intake in the past three months.

In the second part of the survey, we collected data on the health seeking behavior of the PDH at their first experience with the healthcare system. These questions were specifically about the duration of the disease, source of detection, level of health facilities at which the participant sought medical treatment, treatment delay time, and number of visits prior to diagnosis.

In the third part of the survey, information on the demographic and socio-economic characteristics of the PDH (i.e., individual factors) was collected. These questions assessed socio-economic factors such as gender, age, educational attainment, self-reported health status, and the income level of PDH. The poverty line of poverty-stricken families was determined by the local Chinese government according to the income of the residents (People's Government Of Yunnan Province, 2017).

Finally, we surveyed sample VC about their medical and public health services workload as well as the number of PDH they managed. Specific questions on workload were mainly about the number of physicians in each VC, outpatients in the previous month, villages where the services were offered, and the number of residents involved in the service. In terms of PDH management, we asked for the number of PDH that each VC managed, and the number of new suspected PDH that were detected by each VC in the previous year.

\section{Statistical analysis}

We used logistic regression models to analyze the associations between the regularity of clinical visits and medication adherence, and the first experience with care, while also including individual factors. All statistical analyses were performed using STATA 15.0. 
Full ethical approval for this survey was obtained from the Peking University Institutional Review Board on April 26, 2017 (IRB00001052-17033). The board approved the verbal consent procedure. The verbal consent was obtained from local health departments and participants at the start of the survey.

[1] In principle, we randomly selected eight households within each sample village at the first day. We then reduced from eight to six households in the remaining day because of the heavy workload in the survey. In total, there are 116 villages that include six households for inclusion whereas 6 village including eight households.

\section{Results}

\section{Characteristics of sample PDH}

Characteristics of the PDH in our sample are presented in Table 2. The population was $55 \%$ female and $87 \%$ were over 50 years old (Rows $1 \& 2$ ); $43 \%$ of the respondents had no formal education; $42 \%$ did not graduate from junior high school (Row 3 ); and 162 respondents (55\%) reported poor health status (Row 4). In addition, around one-third of the respondents (31\%) came from households that were below the poverty line (Row 5).

Table 2 Demographic and socio-economic characteristics of the participants 


\begin{tabular}{|c|c|c|c|}
\hline Variable & $\begin{array}{c}\text { Full sample } \\
(\mathrm{N}=292) \\
\mathrm{n}(\%)\end{array}$ & 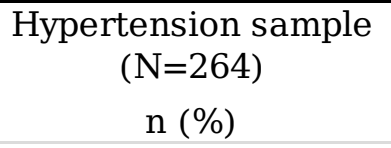 & $\begin{array}{c}\text { Diabetes sample } \\
(\mathrm{N}=48) \\
\mathrm{n}(\%)\end{array}$ \\
\hline \multicolumn{4}{|l|}{ 1. Gender } \\
\hline Male & $132(45)$ & $120(45)$ & $22(46)$ \\
\hline Female & $160(55)$ & $44(55)$ & $26(54)$ \\
\hline \multicolumn{4}{|l|}{ 2. Age } \\
\hline$<50$ & 39 (13) & $33(13)$ & $6(13)$ \\
\hline $50-59$ & $77(26)$ & $68(26)$ & $15(31)$ \\
\hline $60-69$ & $103(35)$ & $94(36)$ & $17(35)$ \\
\hline$>=70$ & $73(25)$ & $69(26)$ & $10(21)$ \\
\hline \multicolumn{4}{|l|}{ 3. Education level } \\
\hline No formal education & $125(43)$ & $111(42)$ & $24(50)$ \\
\hline $1-6$ years study & $123(42)$ & $113(43)$ & $16(33)$ \\
\hline 7-9 years study & $31(11)$ & $27(10)$ & $8(17)$ \\
\hline$>9$ years study & $13(4)$ & $13(5)$ & $0(0)$ \\
\hline \multicolumn{4}{|l|}{$\begin{array}{l}\text { 4. Self-reported health } \\
\text { status }\end{array}$} \\
\hline Not good & $162(55)$ & $144(55)$ & $35(73)$ \\
\hline Medium & $86(29)$ & $78(30)$ & $10(21)$ \\
\hline Good & $44(15)$ & $42(16)$ & $3(6)$ \\
\hline \multicolumn{4}{|l|}{ 5. Poverty-stricken family } \\
\hline Yes & $90(31)$ & $81(31)$ & $18(38)$ \\
\hline No & 202 (69) & $183(69)$ & $30(63)$ \\
\hline
\end{tabular}

Regularity of clinical visits and medication adherence

Table 3 describes the self-management of chronic diseases by survey participants. The survey data shows $73 \%$ of the hypertensive patients (193) and $79 \%$ of the diabetic patients (38) did not consult with a doctor regularly (Row 1). In addition, $40 \%$ of the hypertensive patients (106) and $25 \%$ of the diabetic patients (12) did not take medication regularly in the three months prior to the study (Row 2). In general, around two-fifths (39\%) of the hypertensive patients and a quarter of the diabetic patients neither visited their doctor nor took medicine regularly in the three months prior to the study (Row 3).

Table 3 Clinical visits regularity and medication adherence 
1. Clinical visits regularly last three months Yes $71(27)$ $10(21)$

No

$193(73)$

$38(79)$

2. Medication adherence last three months

Yes

$158(60)$

36 (75)

No

$106(40)$

$12(25)$

3. Clinical visits and medication adherence regularly last three months

Yes

$161(61)$

$36(75)$

No

$103(39)$

$12(25)$

Health care seeking behaviors at first experience with care

The participants were asked to try to recall their health care seeking behavior at their first experience with care (Table 4). In general, more than half of the PDH (63\% and 52\%, respectively) had been diagnosed with hypertension or diabetes in the preceding five years (Row 1). Only $13 \%$ of hypertensive and $17 \%$ of diabetic respondents had the chronic disease for more than 10 years (Row 1). In terms of source of detection, $34 \%$ of the hypertensive patients reported their chronic diseases were detected on visiting the clinic, whereas $41 \%$ of these patients was detected through physical examinations (Row 2). Similarly, $54 \%$ of the participants diagnosed as diabetics reported to have detected their chronic illness through a visit to the clinic, whereas $27 \%$ of the diabetic participants reported that their disease was detected through physical examinations (Row 2).

Table 4 Health care seeking behavior at first experience with care 


\begin{tabular}{|c|c|c|}
\hline Variable & Hypertension sample $(\mathrm{N}=264)$ & Diabetes sample $(\mathrm{N}=48)$ \\
\hline 1. The duration of the chronic disease ${ }^{a}$ & n (\%) & n (\%) \\
\hline Preceding five years & $167(63)$ & $25(52)$ \\
\hline Five years ago & $64(24)$ & $15(31)$ \\
\hline Ten years ago & $33(13)$ & $8(17)$ \\
\hline \multicolumn{3}{|l|}{ 2. Source of detection } \\
\hline $\begin{array}{l}\text { Visiting physicians after clinical } \\
\text { manifestations }\end{array}$ & $91(34)$ & $26(54)$ \\
\hline Physical examination & $108(41)$ & $13(27)$ \\
\hline Other disease visit & $65(25)$ & $9(19)$ \\
\hline \multicolumn{3}{|c|}{ 3. Level of health facilities selected to seek medical treatment at the first time } \\
\hline No treatment & $38(14)$ & $2(4)$ \\
\hline Clinical visits & $205(78)$ & $44(92)$ \\
\hline Village clinic & $63(24)$ & $6(13)$ \\
\hline Township health center & $39(15)$ & $13(27)$ \\
\hline County and upper level of hospitals & $90(34)$ & $25(52)$ \\
\hline Others ${ }^{b}$ & $13(5)$ & $0(0)$ \\
\hline Take medicine at the drugstore & $21(8)$ & $2(4)$ \\
\hline \multicolumn{3}{|l|}{ 4. Treatment delay at the first time } \\
\hline Within 1 week & $150(66)$ & $31(65)$ \\
\hline$>1$ week & $76(34)$ & $17(35)$ \\
\hline \multicolumn{3}{|c|}{ 5. Number of health provider visit before first diagnosis } \\
\hline 1 time & $207(92)$ & $43(94)$ \\
\hline$>1$ time & $19(8)$ & $3(7)$ \\
\hline
\end{tabular}

Note: ${ }^{a}$ If the respondent simultaneously had hypertension and diabetes, we calculated the duration of the chronic disease based on the minimum duration.

${ }^{\mathrm{b}}$ Some participants went to private clinics or sought treatment with traditional Chinese medicine.

We also asked questions relating to the behavior of PDH after they were informed that they had been diagnosed with hypertension or diabetes. Most of the respondents (78\% of the hypertensive and $92 \%$ of the diabetic respondents) reported they sought care from health facilities (Table 4, Row 3). Only a minority ( $8 \%$ of hypertensive respondents and $4 \%$ of diabetic respondents) first chose to buy directly from a drugstore. However, $14 \%$ of those diagnosed with hypertension and $4 \%$ of diabetic respondents had not sought treatment at the time of the survey. More than half of the respondents (66\% and $65 \%)$ had a doctor's appointment within one week of being diagnosed, and most of them ( $92 \%$ and $94 \%$ respectively) were diagnosed for the first time (Row 5).

\section{Factors affecting the regularity of clinical visits and medication adherence}

Table 5 identifies factors associated with regular clinical visits or regular medicine intake in the previous three months. Among the $292 \mathrm{PDH}$, results of the multivariate logistic regression analyses indicated that, apart from gender, the other individual variables were correlated with the regularity of medicinal intake as well (Rows 1 to 5). Specifically, compared with PDH aged below 50, older PDH were more likely to exhibit 
regularity in behavior (Row 2). Moreover, it seems literate patients and patients with a poor health status visited physicians and took medicine more regularly (Rows $3 \& 4$ ). Economic factors, such as the income level of the household, were also significantly associated with regular health behavior patterns of PDH (Row 5).

Table 5 Results of the multivariate logistic regression analyses examining factors associated with regular clinical visits and medication adherence

\begin{tabular}{|c|c|c|c|c|}
\hline \multirow[b]{2}{*}{ Variable } & \multicolumn{4}{|c|}{ Clinical visits or medication adherence in the last three months } \\
\hline & Coef & OR & $95 \% \mathrm{CI}$ & $\mathrm{p}$ value \\
\hline \multicolumn{5}{|l|}{ 1. Gender } \\
\hline Male (ref) & & 1.00 & & \\
\hline Female & 0.33 & 1.39 & $0.74-2.61$ & 0.299 \\
\hline \multicolumn{5}{|l|}{ 2. Age } \\
\hline$<50 \square$ ref $\square$ & & 1.00 & & \\
\hline $50-59$ & 1.10 & 3.02 & $1.20-7.59$ & 0.019 \\
\hline $60-69$ & 1.11 & 3.03 & $1.22-7.52$ & 0.017 \\
\hline$>=70$ & 1.03 & 2.79 & $1.09-7.16$ & 0.032 \\
\hline \multicolumn{5}{|l|}{ 3. Education level } \\
\hline No formal education (ref) & & 1.00 & & \\
\hline $1-6$ years study & 0.60 & 1.83 & $0.95-3.53$ & 0.071 \\
\hline 7-9 years study & 0.75 & 2.12 & $0.73-6.17$ & 0.169 \\
\hline$>9$ years study & 1.41 & 4.09 & $0.87-19.28$ & 0.075 \\
\hline \multicolumn{5}{|l|}{ 4. Self-reported health status } \\
\hline Not good (ref) & & 1.00 & & \\
\hline Medium & -0.72 & 0.49 & $0.26-0.90$ & 0.022 \\
\hline Good & -0.69 & 0.50 & $0.22-1.14$ & 0.099 \\
\hline \multicolumn{5}{|l|}{ 5. Poverty-stricken family } \\
\hline Yes (ref) & & 1.00 & & \\
\hline No & 0.68 & 1.97 & $1.08-3.62$ & 0.028 \\
\hline \multicolumn{5}{|c|}{ 6. Clinical visits at first experience with care } \\
\hline Yes (ref) & & 1.00 & & \\
\hline No & -1.95 & 0.14 & $0.07-2.90$ & $<0.001$ \\
\hline \multicolumn{5}{|c|}{ 7. The duration of the chronic disease } \\
\hline Preceding five years & & 1.00 & & \\
\hline Five years ago & 0.45 & 1.58 & $0.81-3.08$ & 0.184 \\
\hline Ten years ago & 0.24 & 1.28 & $0.52-3.12$ & 0.593 \\
\hline
\end{tabular}

Additionally, the first experience with care by PDH was also found to be associated with regular health behavior patterns (Rows 6 \& 7). Compared to their counterparts, PDH who chose to see a doctor at the first experience with care were more likely to be regular in their hospital visits and medicinal intake (Row 6). Meanwhile, the duration that had passed since the individual had been diagnosed with a chronic disease was not found to be significantly associated with the regularity with which individuals visited the hospitals or took their medicine (Row 7). 
On average, each sample VC had about two physicians (Table 6, Row 1). According to the survey data, these VCs provided both medical and public health services. Around 451 outpatients were seen at a typical VC in the month preceding the survey (Row 2). Each VC provided public health services (including chronic management) to about one village, which accounted for 3,032 rural residents on an average (Rows $3 \& 4$ ). Specifically, around 180 hypertensive patients and 45 diabetic patients were managed by each VC. On an average, 15 individuals were diagnosed as hypertensive whereas 4 individuals were diagnosed as diabetic at a typical VC in the previous year.

Table 6 Hypertension and diabetes management among sample village clinics

\begin{tabular}{lcc}
\hline & Mean & SD \\
\hline Number of physicians per VC & 2.03 & 0.98 \\
\hline Number of outpatients per VC previous month & 450.63 & 650.91 \\
\hline Number of villages each VC provided public health services & 1.03 & 0.46 \\
\hline Population per VC & 3032.15 & 1602.56 \\
\hline Number of patients managed per VC ${ }^{\text {a }}$ & \\
\hline Hypertension & 179.70 & 125.99 \\
\hline Diabetes & 44.51 & 39.14 \\
\hline Number of new suspected patients that were diagnosed last year & \\
\hline Hypertension & 14.58 & 19.65 \\
\hline Diabetes & 3.50 & 5.25 \\
\hline
\end{tabular}

a All of the sample village clinics reported responsible for providing public health services. Only one of these clinics reported not responsible for diabetes.

\section{Discussion}

This study explored the regularity of clinical visits and medication adherence among PDH in rural areas of Yunnan province in China. First, the data indicated that only $61 \%$ of hypertensive and $75 \%$ of diabetic patients went to see doctors or took medication regularly. Second, these patients also reported their health seeking behavior at the first experience with care and a proportion of them did not initially seek care from health facilities. Third, factors including individual characteristics and the first experience with care are significantly associated with regular healthcare behaviors of PDH. Fourthly, in addition to providing medical services, each sample VC with around two physicians managed 180 hypertensive and 45 diabetic patients on an average.

Although low-cost medication and health services of rural primary physicians were currently available due to the health care reforms launched in 2009, PDH self-management was still unsatisfactory. Consistent with other findings in China, our study shows that a proportion of PDH in rural Yunnan province were not able to manage their chronic illnesses effectively (Hu et al., 2019; L. Li et al., 2018; L. Wang et al., 2017). Specifically, $39 \%$ of hypertensive and $25 \%$ of diabetic respondents in the sample neither went to see a doctor nor took medication regularly in 2018. Given that there are more than 244.5 
million hypertensive and 116.4 million diabetic patients in rural China, the erratic behavior of these individuals will be a major challenge to the Chinese government's efforts to control these diseases (International Diabetes Federation, 2019; Z. Wang et al., 2018). This highlights the urgency for more investments in primary health care, which is the first line of defense in the control of diabetes and hypertension. Improvements in primary healthcare could strengthen the ability of the state to educate the people on, and to supervise the management of, chronic diseases in rural China (Campbell \& Sheldon, 2010; Campbell \& Zhang, 2018).

While most PDH sought care from health facilities when they noticed they were suffering from a chronic disease, some PDH in the sample (38 hypertensive and 2 diabetic respondents) still had not sought any medical treatment on the day of the survey. As previous studies have suggested, improving the awareness of PDH in rural China with regard to the self-management of their diseases is imperative (Dong et al., 2014; Lu et al., 2014; He et al., 2016; L. Li et al., 2018). Additionally, among the attending PDH, some patients (34\% hypertensive and $52 \%$ diabetic respondents) preferred higher-tier hospitals as their first source of care. This is partly due to the relative lack of trust in primary health facilities (Feng et al., 2016). However, most of the PDH in the sample were diagnosed on the first visit. This indicates that the capacity of primary health care in rural China has been much improved as previous findings suggested (Hou et al., 2016). Improving the confidence of PDH with regard to the professionalism of rural primary physicians may increase the utilization of primary health services (Browning et al., 2015).

To understand the groups of PDH who are particularly susceptible to irregular behavior, we examined the effect of individual socio-economic characteristics of the PDH including gender, age, educational level, health status and economic status on the proclivity to engage in irregular behavior. Our results suggested that younger and illiterate PDH, PDH who consider themselves to be in good health, and PDH from low income families were more likely to exhibit irregular behavior in terms of health management. In line with some previous studies, patient age, health status and socioeconomic factors are determinants of regular healthcare service utilization (Bhattacharyya et al., 2011; Egan et al., 2010; M. Li \& Wang, 2017; Tang, Bishwajit, et al., 2016; Tang, Ji, et al., 2016).

Our results also emphasize the importance of recognizing the previous experiences of PDH. Their first experiences with care were found to be associated with regular healthcare service utilization as well as regular medication intake. In line with earlier evidence, this finding suggests that seeking care from health facilities at an early stage promotes better control of hypertension and diabetes (Z. Xu et al., 2020). In fact, some studies further point out that not only whether $\mathrm{PDH}$ received care from health providers but also how previous care was given influences the self-management of PDH (Fortuna et al., 2018). It also uncovered the benefits of educating and supervising PDH on their initial health behaviors.

However, results from our investigation into the workload of sample VCs show that village physicians may face challenges in improving their service quality in the management of chronic diseases. Consistent with other findings in rural China, each sample VC with two physicians not only provided medical services for hundreds of outpatients every month but also delivered public health services to one 
village with thousands of people (Hou et al., 2016; Tian et al., 2013). This explained why these physicians could not effectively educate patients and supervise their behavior regarding the management of the chronic illnesses. Lack of human resources in the primary health system is one possible reason for the poor self-management of PDH (Hipgrave, 2011; Yip et al., 2012).

There are several limitations to this study. First, since the data is gathered from the rural areas of Yunnan province, the findings can only be generalized to this population. Second, we only surveyed the population that had already been diagnosed with diabetes or hypertension. We were not able to include the undiagnosed PDH in the survey.

In conclusion, we found that some PDH did not visit physicians or take medication regularly in the rural areas of Yunnan province. Individual characteristics of the PDH (i.e., age, health status, and economic factors) and the first experience with care were found to be significantly associated with regular intake of medicine as well as regular visits to the hospital. Our findings suggested the urgency of improving the ability of PDH to manage their chronic illnesses and taking adequate steps to address the shortage of primary health providers in rural China. To address the problem of poor self-management, standardized education programs should be launched to enhance the knowledge on health measures. In addition, adequate protocols for the supervision of PDH need to be developed. These measures stress the importance of increasing the resources that the Chinese government invests in public health.

\section{References}

Bhattacharyya, O., Delu, Y., Wong, S. T., \& Bowen, C. (2011). Evolution of primary care in China 19972009. Health Policy, 100(2-3), 174-180. https://doi.org/10.1016/j.healthpol.2010.11.005

Browning, C. J., Yang, H., Zhang, T., Chapman, A., Liu, S., Enticott, J., \& Thomas, S. A. (2015).

Implementing a Chronic Disease Self-Management Program into China: The Happy Life Club ${ }^{\text {TM }}$. Frontiers in Public Health, 2. https://doi.org/10.3389/fpubh.2014.00181

Campbell, N. R. C., \& Sheldon, T. (2010). The Canadian effort to prevent and control hypertension: Can other countries adopt Canadian strategies?: Current Opinion in Cardiology, 25(4), 366-372.

https://doi.org/10.1097/HCO.0b013e32833a3632

Campbell, N. R. C., \& Zhang, X.-H. (2018). Hypertension in China: Time to Transition From Knowing the Problem to Implementing the Solution. Circulation, 137(22), 2357-2359.

https://doi.org/10.1161/CIRCULATIONAHA.118.034028

CPC Central Committee, \& State Council. (2009). Opinions on Deepening the Reform of the Medical and Health System.

Dong, S., Xing, F., Wu, B., \& Liu, H. (2014). Cross-sectional investigation of the knowledge of diabetes and levels of self-management among patients with Type II diabetes in rural areas. Modern Preventive 
Medicine, 41(2), 240-245.

Egan, B. M., Zhao, Y., \& Axon, R. N. (2010). US Trends in Prevalence, Awareness, Treatment, and Control of Hypertension, 1988-2008. JAMA, 303(20), 2043-2050. https://doi.org/10.1001/jama.2010.650

Feng, D., Serrano, R., Ye, T., Tang, S., Duan, L., Xu, Y., Yang, J., Liang, Y., Chen, S., Feng, Z., \& Zhang, L. (2016). What Contributes to the Regularity of Patients with Hypertension or Diabetes Seeking Health Services? A Pilot Follow-Up, Observational Study in Two Sites in Hubei Province, China. International Journal of Environmental Research and Public Health, 13(12), 1268.

https://doi.org/10.3390/ijerph13121268

Fortuna, R. J., Nagel, A. K., Rocco, T. A., Legette-Sobers, S., \& Quigley, D. D. (2018). Patient Experience With Care and Its Association With Adherence to Hypertension Medications. American Journal of Hypertension, 31(3), 340-345. https://doi.org/10.1093/ajh/hpx200

GBD 2013 Mortality and Causes of Death Collaborators. (2015). Global, regional, and national age-sex specific all-cause and cause-specific mortality for 240 causes of death, 1990-2013: A systematic analysis for the Global Burden of Disease Study 2013. The Lancet, 385(9963), 117-171. https://doi.org/10.1016/S0140-6736(14)61682-2

GBD 2016 Causes of Death Collaborators. (2017). Global, regional, and national age-sex specific mortality for 264 causes of death, 1980-2016: A systematic analysis for the Global Burden of Disease Study 2016. The Lancet, 390, 1151-1210. https://doi.org/10.1016/S0140-6736(17)32152-9

He, C., Zhang, Y., Li, C., Li, Z., Zhao, Y., Bai, R., \& Li, Y. (2016). Analysis of the current status of selfmanagement skills among patients with hypertension and diabetes in Shunyi District in Beijing City. Modern Preventive Medicine, 43(20), 3729-3732.

Hipgrave, D. (2011). Perspectives on the progress of China's $2009-2012$ health system reform. Joural of Global Health, 1(2), 142-147.

Hou, Z., Meng, Q., \& Zhang, Y. (2016). Hypertension Prevalence, Awareness, Treatment, and Control Following China's Healthcare Reform. American Journal of Hypertension, 29(4), 428-431.

https://doi.org/10.1093/ajh/hpv125

Hu, S., Gao, R., Liu, L., Zhu, M., Wang, W., Wang, Y., Wu, Z., Li, H., Gu, D., Yang, Y., Zheng, Z., \& Chen, W. (2019). Summary of the 2018 Report on Cardiovascular Diseases in China. Chinese Circulation Journal, 34(3), 209-220.

Huang, C., Zhou, H., Xiong, J., \& Peng, J. (2006). Survey of knowledge, attitude and behavior of diabetic patients managed by community and analysis of influential factors. China Tropical Medicine, 06(10), 1903-1905.

International Diabetes Federation. (2019). IDF Diabetes Atlas Ninth edition. 
Lei, X., Yin, N., \& Zhao, Y. (2012). Socioeconomic status and chronic diseases: The case of hypertension in China. China Economic Review, 23(1), 105-121. https://doi.org/10.1016/j.chieco.2011.08.004

Li, H., Liu, F., \& Xi, B. (2014). Control of hypertension in China: Challenging. International Journal of Cardiology, 174(3), 797. https://doi.org/10.1016/j.ijcard.2014.04.121

Li, L., Li, X., Kong, H., Liu, Y., Yang, H., \& Cai, L. (2018). Prevalence, control and selfmanagement of hypertension among elderly residents in rural areas of Yunnan province. Chin J Public Health, 34(5), 690-692.

Li, M., \& Wang, C. (2017). The Association Between the New Rural Cooperative Medical System and Health Care Seeking Behavior Among Middle-Aged and Older Chinese. Journal of Aging \& Social Policy, 29(2), 168-181. https://doi.org/10.1080/08959420.2016.1220225

Li, Y., Wang, J. L., Zhang, X. C., Liu, D., Shi, W. H., Liang, X. F., \& Wu, J. (2016). Effectiveness of Adherence to Standardized Hypertension Management by Primary Health Care Workers in China: A Cross-sectional Survey 3 Years after the Healthcare Reform. Biomedical and Environmental Sciences, 29(12), 915-921. https://doi.org/10.3967/bes2016.123

Lu, Y., Meng, Q., \& Sun, X. (2014). Studying on the self-management and control of hypertension and diabetes in rural Shandong $囚$. The Chinese Health Service Management, 5, 386-389.

Ma, D., Sakai, H., Wakabayashi, C., Kwon, J.-S., Lee, Y., Liu, S., Wan, Q., Sasao, K., Ito, K., Nishihara, K., \& Wang, P. (2017). The prevalence and risk factor control associated with noncommunicable diseases in China, Japan, and Korea. Journal of Epidemiology, 27(12), 568-573.

https://doi.org/10.1016/j.je.2016.12.019

National Bureau of Statistics of China. (2019). China statistical yearbook 2019. China Statistics Press. National health and family planning commission. (2017). China health and family planning statistical yearbook 2017.

People's Government Of Yunnan Province. (2017). Yunnan Province 2016 National Economic and Social Development Statistical Bulletin.

Tang, S., Bishwajit, G., Ji, L., Feng, D., Fang, H., Fu, H., Shao, T., Shao, P., Liu, C., Feng, Z., \& Luba, T. R. (2016). Improving the Blood Pressure Control With the ProActive Attitude of Hypertensive Patients Seeking Follow-up Services: Evidence From China. Medicine, 95(14).

https://doi.org/10.1097/MD.0000000000003233

Tang, S., Ji, L., Hu, T., Bishwajit, G., Da Feng, Ming, H., Xian, Y., Fu, Q., He, Z., Fu, H., Wang, R., \& Feng, Z. (2016). Determinants of public malaria awareness during the national malaria elimination programme: $A$ cross-sectional study in rural China. Malaria Journal, 15(1), 372-380. https://doi.org/10.1186/s12936016-1427-y 
Tian, M., Feng, D., Chen, X., Chen, Y., Sun, X., Xiang, Y., Yuan, F., \& Feng, Z. (2013). China's Rural Public Health System Performance: A Cross-Sectional Study. PLoS ONE, 8(12), e83822.

https://doi.org/10.1371/journal.pone.0083822

Wang, L., Gao, P., Zhang, M., Huang, Z., Zhang, D., Deng, Q., Li, Y., Zhao, Z., Qin, X., Jin, D., Zhou, M., Tang, X., Hu, Y., \& Wang, L. (2017). Prevalence and Ethnic Pattern of Diabetes and Prediabetes in China in 2013. JAMA, 317(24), 2515-2523. https://doi.org/10.1001/jama.2017.7596

Wang, Z., Chen, Z., Zhang, L., Wang, X., Hao, G., Zhang, Z., Shao, L., Tian, Y., Dong, Y., Zheng, C., Wang, J., Zhu, M., Weintraub, W. S., \& Gao, R. (2018). Status of Hypertension in China: Results From the China Hypertension Survey, 2012-2015. Circulation, 137(22), 2344-2356.

https://doi.org/10.1161/CIRCULATIONAHA.117.032380

Xu, Y., Wang, L., He, J., Bi, Y., Li, M., Wang, T., Wang, L., Jiang, Y., Dai, M., Lu, J., Xu, M., Li, Y., Hu, N., Li, J., Mi, S., Chen, C.-S., Li, G., Mu, Y., Zhao, J., ... Ning, G. (2013). Prevalence and Control of Diabetes in Chinese Adults. JAMA, 310(9), 948-958. https://doi.org/10.1001/jama.2013.168118

Xu, Z., Yang, J., Hu, J., Song, Y., He, W., Luo, T., Cheng, Q., Ma, L., Luo, R., Fuller, P. J., Cai, J., Li, Q., Yang, S., Mei, M., Luo, S., Liao, K., Zhang, Y., He, Y., He, Y., ... Peng, B. (2020). Primary Aldosteronism in Patients in China With Recently Detected Hypertension. Journal of the American College of Cardiology, 75(16), 1913-1922. https://doi.org/10.1016/j.jacc.2020.02.052

Yip, W. C.-M., Hsiao, W. C., Chen, W., Hu, S., Ma, J., \& Maynard, A. (2012). Early appraisal of China's huge and complex health-care reforms. Lancet, 379, 833-842. https://doi.org/10.1016/S0140-6736(11)618801

\section{Supplementary Files}

This is a list of supplementary files associated with this preprint. Click to download.

- Datastatement.docx 